\title{
-
}

RESEARCH AND EDUCATION

\section{Effects of whitening dentifrice on yttria-stabilized tetragonal zirconia polycrystal surfaces after simulating brushing}

\author{
Lígia Antunes Pereira Pinelli, DDSc, PhD, ${ }^{a}$ Amanda Caroline Gimenes Olbera, ${ }^{\mathrm{b}}$ Lucas Miguel Candido, \\ Larissa Natiele Miotto, ${ }^{d}$ Selma Gutierrez Antonio, DDSc, PhD, ${ }^{e}$ and Laiza Maria Grassi Fais, DDSc, PhD
}

The perfect white smiles shown in the media have had an undeniable effect on the demand for esthetic procedures in dentistry. ${ }^{1}$ Dentists have adopted procedures from the less invasive products, such as use of whitening products, to tooth preparations for metal-free crowns and fixed prosthodontics. Meanwhile manufacturers of oral care products have developed new tooth whitening approaches and general improvements., ${ }^{2,3}$

The improvements in smile esthetics provided by professional bleaching systems have stimulated the marketing of self-applied whitening treatments that can be harmful. ${ }^{4}$ Whitening dentifrices formulated by incorporating abrasive, chemical, and optical agents have become popular but can have adverse effects on the surfaces of restorative materials. ${ }^{2,5}$

Among ceramic materials, yttria-stabilized tetragonal zirconia polycrystal (Y-TZP) has been the focus of

\begin{abstract}
Statement of problem. The changes that occur after brushing yttria-stabilized tetragonal zirconia polycrystal (Y-TZP) are unknown. These changes may favor the retention of microorganisms and chemisorption of water, impairing its longevity.
\end{abstract}

Objective. The purpose of this in vitro study was to evaluate the effects of a whitening dentifrice on Y-TZP surfaces after simulating 10 years of brushing.

\begin{abstract}
Material and methods. Seventy-two bar-shaped specimens $(20 \times 4 \times 1.2 \mathrm{~mm})$ were divided into 4 groups: storage in distilled water (SW, control), brushing with distilled water (BW), brushing with dentifrice (BD), and brushing with whitening dentifrice (BWD). Brushing was conducted using a linear brushing machine (878 400 cycles, $0.98 \mathrm{~N}$, soft toothbrush). The mean roughness (Ra) was analyzed with a profilometer and the superficial topography with scanning electron microscopy (SEM) at baseline and after treatment. Crystalline phases were characterized using $\mathrm{x}$-ray diffraction. Baseline and posttreatment Ra were analyzed using the 1-way ANOVA and Tukey HSD multiple comparison test; the paired $t$ test was used for intragroup comparison (all $\alpha=.05$ ).
\end{abstract}

Results. The Ra $(\mu \mathrm{m})$ means (before/after treatment) were SW 0.28/0.28; BW 0.32/0.31; BD 0.28/0.36; BWD 0.30/0.20. No statistically significant difference was found for Ra at baseline $(P=.108)$ than for posttreatment results $(P<.001)$; the BD group had higher Ra values when compared with baseline $(P=.019)$; the BWD group had the lowest values $(P<.001)$. The BD surfaces showed pronounced scratches and detachment of the surface, while BWD showed smoother surfaces; similar crystallographic results among groups were observed.

Conclusions. Brushing Y-TZP with conventional dentifrice increased roughness, while brushing with whitening dentifrice reduced roughness. Neither dentifrice changed the crystallographic phases after brushing. (J Prosthet Dent 2017;117:158-163)

interest because of its high flexural strength ${ }^{6}$ and resistance to fracture associated with good biocompatibility, good frictional behavior, and wear resistance. ${ }^{7}$ In addition, its high corrosion resistance to acids and alkalis ${ }^{7}$

Supported by grant PIBIC/CNPq/UNESP.

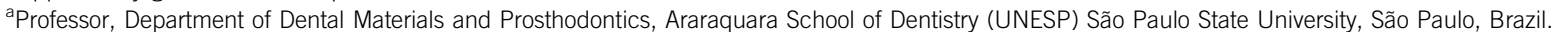

bUndergraduate student, Department of Dental Materials and Prosthodontics, Araraquara School of Dentistry (UNESP) São Paulo State University, São Paulo, Brazil.

${ }^{\circ}$ Graduate student, Department of Dental Materials and Prosthodontics, Araraquara School of Dentistry (UNESP) São Paulo State University, São Paulo, Brazil.

${ }^{d}$ Graduate student, Department of Dental Materials and Prosthodontics, Araraquara School of Dentistry (UNESP) São Paulo State University, São Paulo, Brazil.

ePostdoctoral Researcher, Department of Physical Chemistry, Araraquara School of Dentistry (UNESP) São Paulo State University, São Paulo, Brazil.

fPostdoctoral Researcher, Department of Dental Materials and Prosthodontics, Araraquara School of Dentistry (UNESP) São Paulo State University,

São Paulo, Brazil. 


\section{Clinical Implications}

The search for white teeth drives the use of whitening dentifrices associated with the use of more esthetic restorative materials such as ceramics. Clinically, the effect of the abrasiveness and chemical composition of this kind of dentifrice on the surface of Y-TZP zirconia exposed to the oral environment is unknown. Surfaces with fewer irregularities have less plaque accumulation.

allows it to be used for implants and abutments, copings, ${ }^{8}$ brackets, ${ }^{9-13}$ and anatomic-contour crowns (monolithic zirconia). ${ }^{14,15}$ It is the best material to use to resist high stress on posterior metal-free prostheses. ${ }^{10}$

However, Y-TZP is susceptible to unwanted crystalline phase transformation that could be triggered by external factors such as mechanical stress, aging, and chemistry. ${ }^{16-20}$ As a result of this transformation, zirconia surfaces may show grain loss, increased roughness, and decreased hardness and resistance. ${ }^{21-24}$ Superficial roughness plays a significant role in biofilm formation ${ }^{25}$ because irregularities can shelter microorganisms and protect them from salivary flow, mastication, swallowing, and oral hygiene, ${ }^{26,27}$ thus favoring microbial colonization and possibly failure of the material. The critical roughness threshold for biofilm formation has been reported to be $0.2 \mathrm{~mm} .{ }^{28}$ Because surface roughness on the order of $0.3 \mathrm{~mm}$ can be detected by the tip of the patient's tongue, a smoother surface provides comfort for the patient. $^{29}$

Despite the importance of toothbrushing for the maintenance of oral health, ${ }^{30}$ it can lead to mechanical and chemical stress in the restorative materials, especially composite resins. ${ }^{31-33}$ Although this has the least influence on ceramic surfaces, ${ }^{34-36}$ the instability of Y-TZP due to its phase transformation highlights the necessity of evaluating the effects of toothbrushing on this material.

The purpose of this study was to evaluate the roughness, superficial topography, and crystalline phases of Y-TZP, simulating 10 years of brushing using whitening and conventional fluoride toothpastes. The null hypothesis was that 10 years of brushing with whitening and conventional fluoride toothpaste does not change the properties of Y-TZP zirconia.

\section{MATERIAL AND METHODS}

After a pilot study, and considering specimen calculation to obtain a statistical test power equal to $0.80,72$ barshaped specimens $(25 \times 5 \times 1.5 \mathrm{~mm})$ were cut from presintered blocks of Y-TZP zirconia (Lava Frame Zirconia; 3M ESPE AG). A low-speed diamond disk (Series 15LC
Table 1. Experimental groups, toothpaste manufacturers, and compositions

\begin{tabular}{lcl}
\hline Group & Manufacturer & \multicolumn{1}{c}{ Composition } \\
\hline SW & - & \multicolumn{1}{c}{-} \\
\hline BW & - & \multicolumn{1}{c}{-} \\
\hline BD & $\begin{array}{l}\text { Oral-B 1.2.3, Procter \& } \\
\text { Gamble do Brasil S/A }\end{array}$ & $\begin{array}{l}\text { Sodium monofluorophosphate (1450 } \\
\text { ppm F-), calcium carbonate, water, } \\
\text { sorbitol, sílica, sodium lauryl sulphate, } \\
\text { celulose gum, flavor, trisodium } \\
\text { phosphate, sodium saccharin, sodium } \\
\text { phosphate, limonene }\end{array}$ \\
& & $\begin{array}{l}\text { Sodium fluoride (1450 ppm F'), disodium } \\
\text { pyrophosphate, water, hydrated silica, } \\
\text { sorbitol, sodium lauryl sulfate, flavor, } \\
\text { sodium hydroxide, cellulose gum, Mica/Cl }\end{array}$ \\
& $\begin{array}{l}\text { Oral-B 3D White, Procter \& } \\
\text { Gamble Manufacturing } \\
\text { GMBH }\end{array}$ & $\begin{array}{l}\text { 47891, Polyethylene/Blue 1 Lake (Cl } \\
\text { carbomer, limonene }\end{array}$ \\
\hline
\end{tabular}

SW, storage in distilled water; BW, brushing with distilled water; BD, brushing with dentrifice; BWD, brushing with whitening dentrifice.

Diamond; Buehler) in a high precision sectioning saw (Isomet 1000; Buehler) was used under water cooling. ${ }^{35}$ The bars were polished with abrasive papers (45 $\mu \mathrm{m}$ and $15 \mu \mathrm{m}$ Ultra-Prep; Buehler) and diamond suspensions $(15 \mu \mathrm{m}$, MetaDi Supreme Polycrystalline Diamond Suspension; Buehler).

The bars were sintered in a furnace (Lava Furnace 200; $3 \mathrm{M}$ ESPE AG) for 8 hours at $1500^{\circ} \mathrm{C}$, according to the manufacturer's instructions. Final dimensions, considering approximately $20 \%$ volumetric shrinkage, were $20 \times 4 \times 1.2 \mathrm{~mm}$. The specimens were divided into 4 groups $(n=18)$ : storage in distilled water (SW, control), brushing with distilled water (BW), brushing with dentifrice (BD), and brushing with whitening dentifrice (BWD), as listed in Table 1.

The specimens were brushed using a linear brushing machine (Mavtec Comércio e Serviços) equipped with soft bristle toothbrush heads (\#35, Oral-B Indicator; Procter \& Gamble Brazil S/A) using distilled water (BW), conventional fluoride dentifrice slurry (BD), or whitening dentifrice slurry (BWD). The machine was set to brush at a rate of 60 reciprocal strokes per minute, with a vertical load of $0.98 \mathrm{~N}^{32,37}$ for 244 hours. ${ }^{27}$

Slurries of dentifrice were prepared by mixing 2 parts of distilled water $(\mathrm{mL})$ and 1 part of dentifrice $(\mathrm{g})^{38}$ in a magnetic mixer for 10 minutes. Brushes and slurries were replaced after 44160 cycles. ${ }^{27}$ The SW (control) specimens remained submersed in distilled water for 244 hours.

The $\mathrm{pH}$ of the slurries was measured at baseline and after 24 hours using a calibrated digital potentiometer (Q400AS; Quimis), only once for each of the 2 slurries, at a dilution of $5 \mathrm{~g}$ of dentifrice suspended in $10 \mathrm{~mL}$ of distilled water.

Mean roughness (Ra) was analyzed with an accuracy of $0.01 \mu \mathrm{m}$ at baseline and after treatment using a profilometer (Mitutoyo SJ 400; Mitutoyo Corp) at the 3 following locations: length of $2.5 \mathrm{~mm}$, active tip radius of $5 \mu \mathrm{m}$, and speed of $0.5 \mathrm{~mm} / \mathrm{s}$. 
Table 2. Mean of Ra ( $\mu \mathrm{m})$ according to experimental groups

\begin{tabular}{lcccc}
\hline Measurement & SW & BW & BD & BWD \\
\hline Baseline & $0.28^{\mathrm{Aa}}$ & $0.32^{\mathrm{Aa}}$ & $0.28^{\mathrm{Aa}}$ & $0.30^{\mathrm{Aa}}$ \\
\hline After treatment & $0.28^{\mathrm{Aa}}$ & $0.31^{\mathrm{Aa}}$ & $0.36^{\mathrm{Aa}}$ & $0.20^{\mathrm{Bb}}$
\end{tabular}

$\mathrm{SW}$, storage in distilled water; BW, brushing with distilled water; BD, brushing with dentrifice BWD, brushing with whitening dentrifice. Different superscript uppercase letters indicate statistically significant differences $(P<.05)$ between rows; different superscript lowercase letters indicate statistically significant differences $(P<.05)$ among columns.

Posttreatment images for all groups were obtained using a scanning electron microscope (JSM 6610LV; JEOL) with magnifications of $\times 500, \times 1000$, and $\times 3000$. Crystalline phase analysis was executed using an $\mathrm{x}$-ray diffractometer (D8-Advance; Bruker Corp) at $2 \theta$ range between 20 and 80 degrees with step size of 0.02 degree in continuous mode of 1.8 degrees/min. The relative amounts of crystalline structures (monoclinic, tetragonal, and cubic phases) were determined with $x$-ray powder diffraction data using the Rietveld method. ${ }^{39,40}$

Baseline and posttreatment Ra were analyzed using 1-way ANOVA followed by the Tukey HSD multiple comparison test to evaluate differences among the testing groups; the paired $t$ test (all $\alpha=.05$ ) was used for comparison within the same group, both before and after treatment.

\section{RESULTS}

Mean Ra values are listed in Table 2. At baseline, all groups showed similar $\mathrm{Ra}$ values $(P=.108)$, indicating standardization of the specimens. Differences were observed between groups after the simulated brushing $(P<.001)$. When the initial and final values were compared, an increase in the values for group $\mathrm{BD}$ $(P=.019)$ and a decrease for group BWD $(P<.001)$ were observed.

SEM micrographs of the SW and BW (Fig. 1A, B) surfaces revealed scratches caused by polishing procedures and grains with similar sizes; there was an increase in the number of pores in the BW surface (Fig. 1B). The surface of the $\mathrm{BD}$ group displayed a detachment of surface sheets (Fig. 1C). In contrast, the surface brushed with the whitening dentifrice was smoother (Fig. 1D) but showed increased porous radii.

The $x$-ray powder diffraction is shown in Figure 2. Similar crystallographic results among groups were observed; no significant differences were found regarding the quantitative phase analyses (Table 3) obtained using the Rietveld 39,40 method. The $\mathrm{pH}$ values of the slurry were 8.78 for $\mathrm{BD}$ and 7.67 for BWD.

\section{DISCUSSION}

Brushing effects on the surface properties of dental materials are usually evaluated using simulated toothbrushing abrasion tests. This is considered an established model in the literature ${ }^{33}$ and is a parameter for measuring smoothness, color stability, and loss of gloss, even without the ability to simulate specific proteins and ions of saliva, which may diminish the roughening effect during toothbrushing. ${ }^{35}$

Little information is available about the effect of toothbrushing and dentifrices on the surface properties of current dental materials, including ceramics. ${ }^{35}$ Presumably, this is due to the higher wear resistance and higher hardness of these materials. However, the effect of toothbrushing on Y-TZP should be investigated because it is susceptible to the low temperature degradation that occurs in moist environments. ${ }^{7,21,23}$ Cracking or chipping of ceramic veneers, overdentures with zirconia abutments, telescopic partial fixed dental prostheses with zirconia copings, ${ }^{8}$ in addition to microleakage caused by the dissolution of conventional cements, may expose zirconia to direct contact with a moist environment.

Even with the higher hardness that contributes to increased wear resistance, the results found in this study showed that all zirconia specimens brushed with dentifrice (BD and BWD) changed in terms of roughness and superficial topography. This led to the rejection of the null hypothesis.

The Ra values obtained from the specimens used in this study agree with the values obtained in other studies in which the $\mathrm{Ra}$ values ranged from 0.18 to 0.98 $\mu \mathrm{m} .{ }^{15,25,37}$ No significant changes were found after immersion (control, SW group) and brushing with water (BW group). However, Ra values increased after brushing with conventional dentifrice (BD group), and there was a polishing effect on surfaces that were brushed with whitening dentifrice (BWD group). Even the roughest surfaces (BD group) were clinically acceptable in that they were within the Ra range from $0.25 \mu \mathrm{m}$ to $0.5 \mu \mathrm{m}$, which is undetectable by the tongue. ${ }^{29}$

Different results, such as unchanged roughness after brushing with conventional dentifrice and roughened ceramic surfaces after brushing with whitening dentifrice, have been published previously. ${ }^{36,37}$ However, comparisons among studies are limited because of the different standards of polishing and smoothness of the surfaces before brushing ${ }^{37}$ and because of the design of the brushing tests, for example, the number of cycles and the force used. ${ }^{36}$

The many variables related to the brushing abrasion test, such as brush type, applied force and frequency, abrasion, and chemical composition of the dentifrice are cited as the main factors ${ }^{35}$ that can change the surfaces of enamel and different restorative materials. Initially, the findings of this study could be explained by the different radioactive dentin abrasion (RDA) values of the dentifrices. However, increased RDA values do not necessarily result in increased roughness, and vice versa. ${ }^{3}$ Thus, the abrasive type, the chemical reaction between detergents 

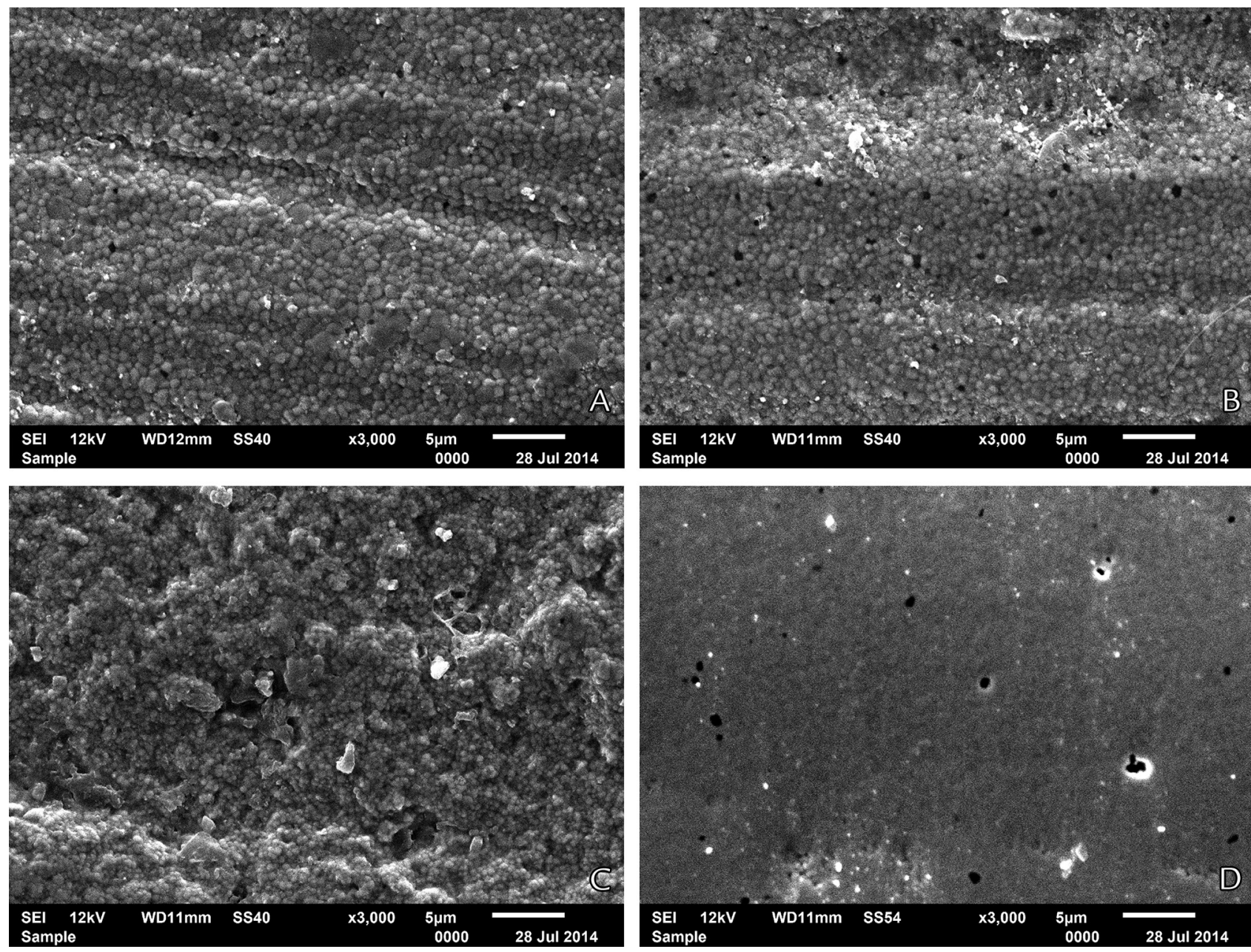

Figure 1. Scanning electron micrographs of groups. A, Storage in distilled water. B, Brushing with distilled water. C, Brushing with dentrifice. D, Brushing with whitening dentrifice. Original magnification $\times 3000 ;$ bar $=5 \mu \mathrm{m}$.

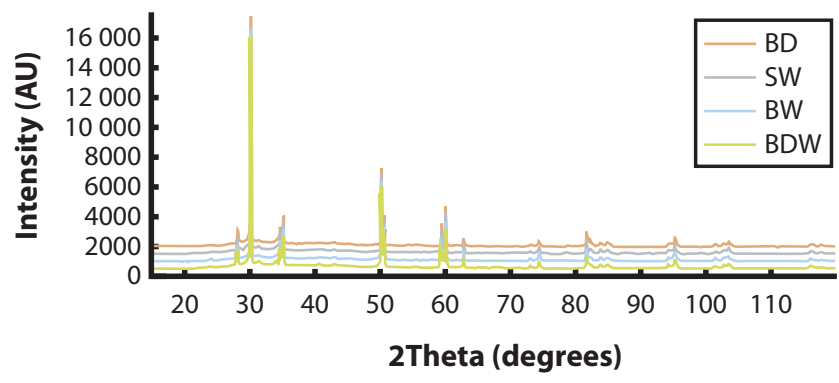

Figure 2. X-ray powder diffraction patterns of experimental groups (SW, storage in distilled water; BW, brushing with distilled water; $\mathrm{BD}$, brushing with dentrifice; BWD, brushing with whitening dentrifice).

and abrasives, the $\mathrm{pH}$, and the rheologic properties of the final slurry can change surfaces in different ways. ${ }^{3,30}$

The abrasiveness of the slurry formed by the dentifrice during brushing is influenced by the physical characteristics of the abrasive particles, namely shape, size, acuteness, hardness, and ductility. ${ }^{31}$ Many different techniques have been reported $^{2,3}$ for analyzing toothpaste
Table 3. Monoclinic, tetragonal, and cubic percentage by mass, according to experimental groups

\begin{tabular}{lcccc}
\hline Crystalline Phase & SW & BW & BD & BWD \\
\hline Monoclinic & 19.67 & 19.33 & 20.22 & 20.59 \\
\hline Tetragonal & 66.31 & 67.78 & 66.33 & 67.51 \\
\hline Cubic & 14.02 & 12.89 & 13.45 & 11.91 \\
\hline
\end{tabular}

SW, storage in distilled water; BW, brushing with distilled water; $B D$, brushing with dentrifice; BWD, brushing with whitening dentrifice.

abrasiveness and its effects on brushed surfaces. However, the method most frequently applied and discussed in scientific papers is the RDA method, which uses the limit of 250 as the maximum value. ${ }^{3}$ Although the RDA of the whitening dentifrice used in this study had not yet been reported, its RDA can be 2 to 3 times greater than that of conventional dentifrices. ${ }^{3}$

Whitening toothpastes typically contain higher amounts of abrasives and detergents than conventional ones. ${ }^{1}$ Thus, the lower Ra values found for the BWD specimens after brushing can also be explained by the presence of hydrated silica and mica, which are not part 
of conventional dentifrices. Mica is a mild abrasive that is included in some dentifrices to assist with polishing the teeth. Because of the high hardness of the material studied, these components, together with the detergents present in the whitening dentifrice, smoothed the surfaces of the specimens (Fig. 1D).

Another explanation for the findings of this study is probably related to the influence of $\mathrm{pH}$ variations and the concentration of fluoride on the zirconia's susceptibility to degradation. ${ }^{18,19}$ While a neutral $\mathrm{pH}$ does not change the microstructural appearance of zirconia surfaces, alkaline and acid pHs may corrode the surface of the material. ${ }^{19}$ Thus, the increased $\mathrm{Ra}$ of $\mathrm{BD}$ specimens (Table 2), in addition to the micrographs that showed more pronounced scratches and the detachment of surface sheets with rough and sharp grains (Fig. 1C), could be explained by a possible loss of ions due to the alkaline $\mathrm{pH}$ of the slurry of the BD group $(\mathrm{pH}=8.74)$. This is in contrast to the neutral $\mathrm{pH}$ (7.67) of the BWD group, which showed smooth surfaces.

Regarding the crystalline phases after toothbrushing, no change was observed (Table 3), and a percentage by mass of the monoclinic, tetragonal, and cubic phases was similar among all groups. Significant $t \rightarrow m$ phase transformation, due to the loss of chemical metastability, can occur when zirconia is subjected to fluoride environments more acid than those of the slurries used in this study. ${ }^{1}$

The knowledge that brushing Y-TZP zirconia with a whitening dentifrice does not severely compromise the roughness, microstructure, or crystalline phases will reassure the dentist about the use of this prophylactic agent. However, further clinical investigations using saliva, monolithic, and even aged Y-TZP are indicated to better understand the effects of toothbrushing on these materials.

\section{CONCLUSIONS}

Brushing Y-TZP with conventional dentifrice increased roughness, while brushing with whitening dentifrice reduced roughness. Neither dentifrice changed the crystallographic phases of Y-TZP after 10 years of simulated brushing.

\section{REFERENCES}

1. Carey CM. Tooth whitening: what we now know. J Evid Based Dent Pract 2014;14:70-6.

2. Joiner A. Whitening toothpastes: a review of the literature. J Dent 2010;38: $17-24$.

3. Johannsen G, Tellefsen G, Johannsen A, Liljeborg A. The importance of measuring toothpaste abrasivity in both a quantitative and qualitative way. Acta Odontol Scand 2013;71:508-17.

4. Demarco FF, Meireles SS, Masotti AS. Over-the-counter whitening agents: a concise review. Braz Oral Res 2009;23:64-70.

5. Khamverdi Z, Kasraie S, Rezaei-Soufi L, Jebeli S. Comparison of the effects of two whitening toothpastes on microhardness of the enamel and a microhybrid composite resin: an in vitro study. J Dent (Tehran) 2010;7 $139-45$
6. Amer R, Kürklü D, Johnston W. Effect of simulated mastication on the surface roughness of three ceramic systems. J Prosthet Dent 2015:114:260-5.

7. Vagkopoulou T, Koutayas SO, Koidis P, Strub JR. Zirconia in dentistry: Part 1. Discovering the nature of an upcoming bioceramic. Eur J Esthet Dent 2009; $130-51$.

8. Pellecchia R, Kang KH, Hirayama H. Fixed partial denture supported by allceramic copings: a clinical report. J Prosthet Dent 2004;92:220-3.

9. Springate SD, Winchester LJ. An evaluation of zirconium oxide brackets: a preliminary laboratory and clinical report. Br J Orthod 1991;18:203-9.

10. Studart AR, Filser F, Kocher P, Luthy H, Gauckler LJ. Cyclic fatigue in water of veneer-framework composites for all-ceramic dental bridges. Dent Mater 2007;23:177-85.

11. Depprich R, Zipprich H, Ommerborn M, Naujoks C, Wiesmann HP, Kiattavorncharoen S, et al. Osseointegration of zirconia implants compared with titanium: an in vivo study. Head Face Med 2008:4:30.

12. Wenz HJ, Bartsch J, Wolfart S, Kern M. Osseointegration and clinical success of zirconia dental implants: a systematic review. Int J Prosthodont 2008;21: 27-36.

13. Gomes AL, Montero J. Zirconia implant abutments: A review. Med Oral Patol Oral Cir Bucal 2011;16:50-5.

14. Kim HK, Kim SH, Lee JB, Ha SR. Effects of surface treatments on the translucency, opalescence, and surface texture of dental monolithic zirconia ceramics. J Prosthet Dent 2016;115:773-9.

15. Luangruangrong P, Cook NB, Sabrah AH, Hara AT, Bottino MC. Influence of full-contour zirconia surface roughness on wear of glass ceramics. J Prosthodont 2014;23:198-205.

16. Catledge SA, Cook M, Vohra YK, Santos EM, McClenny MD, David Moore K. Surface crystalline phases and nanoindentation hardness of explanted zirconia femoral heads. J Mater Sci Mater Med 2003:14:863-7.

17. Curtis AR, Wright AJ, Fleming GJ. The influence of surface modification techniques on the performance of a Y-TZP dental ceramic. J Dent 2006;34: 195-206.

18. Mukaeda LE, Taguchi SP, Robin A, Izario HI, Salazar RFS, Santos C Degradation of $\mathrm{Y}_{2} \mathrm{O}_{3}$-stabilized $\mathrm{ZrO} 2$ ceramics in artificial saliva: ICP analysis of dissolved $\mathrm{Y}^{3+}$ and $\mathrm{Zr}^{4+}$ ions. Mater Sci Forum 2012;727-8:1136.

19. Turp V, Tuncelli B, Sen D, Goller G. Evaluation of hardness and fracture toughness, coupled with microstructural analysis, of zirconia ceramics stored in environments with different pH values. Dent Mater J 2012;31:891-902.

20. Hallmann L, Ulmer $\mathrm{P}$, Wille $\mathrm{S}$, Polonskyi $\mathrm{O}$, Köbel S, Trottenberg $\mathrm{T}$, et al. Effect of surface treatments on the properties and morphological change of dental zirconia. J Prosthet Dent 2016;115:341-9.

21. Cattani-Lorente M, Scherrer SS, Ammann P, Jobin M, Wiskott HW. Low temperature degradation of a Y-TZP dental ceramic. Acta Biomater 2011;7 858-65.

22. Chevalier I, Loh I, Gremillard L, Meille S, Adolfson E. Low-temperature degradation in zirconia with a porous surface. Acta Biomater 2011;7:2986-93.

23. Kawai Y, Uo M, Wang YM, Kono S, Ohnuki S, Watari F. Phase transformation of zirconia ceramics by hydrothermal degradation. Dent Mater 2011;30:286-92

24. Alghazzawi TF, Lemons J, Liu PR, Essig ME, Bartolucci AA, Janowski GM Influence of low-temperature environmental exposure on the mechanical properties and structural stability of dental zirconia. J Prosthodont 2012;21: 363-9.

25. Kantorski KZ, Valandro LF, Scotti R, Della Bona A, Bottino MA. Surface roughness of glazed feldspar, alumina, and zirconia-based ceramics. Cienc Odontol Bras 2006;9:12-7.

26. Scotti R, Kantorski KZ, Monaco C, Valandro LF, Ciocca L, Bottino MA. SEM evaluation of in situ early bacterial colonization on a Y-TZP ceramic: a pilot study. Int J Prosthodont 2007;20:419-22

27. Fais LM, Fernandes-Filho RB, Pereira-da-Silva MA, Vaz LG, Adabo GL. Titanium surface topography after brushing with fluoride and fluoride-free toothpaste simulating 10 years of use. J Dent 2012;40:265-75.

28. Teughels W, Van Assche N, Sliepen I, Quirynen M. Effect of material characteristics and/or surface topography on biofilm development. Clin Oral Implants Res 2006:17:68-81.

29. Jones CS, Billington RW, Pearson GJ. The in vivo perception of roughness of restorations. Br Dent J 2004;196:42-5.

30. Moore C, Addy M. Wear of dentine in vitro by toothpaste abrasives and detergents alone and combined. J Clin Periodontol 2005;32:1242-6.

31. Turssi CP, Purquerio BM, Serra MC. Wear of dental resin composites: in sights into underlying processes and assessment methods-a review. J Biomed Mater Res B Appl Biomater 2003;65:280-5.

32. Takahashi R, Jin J, Nikaido T, Tagami J, Hickel R, Kunzelmann KH. Surface characterization of current composites after toothbrush abrasion. Dent Mater J 2013;32:75-82

33. Monteiro B, Spohr AM. Surface roughness of composite resins after simulated toothbrushing with different dentifrices. J Int Oral Health 2015;7:1-5.

34. Yesil Duymus Z, Orbak R, Dilsiz A. Abrasion resistance of veneering mate rials to tooth brushing. Dent Mater J 2003;22:460-6.

35. Heintze SD, Forjanic M, Ohmiti K, Rousson V. Surface deterioration of dental materials after simulated toothbrushing in relation to brushing time and load. Dent Mater 2010;26:306-19. 
36. Azevedo SM, Kantorski KZ, Valandro LF, Bottino MA, Pavanelli CA. Effect of brushing with conventional versus whitening dentifrices on surface roughness and biofilm formation of dental ceramics. Gen Dent 2012;60: 123-30.

37. Candido LM, Fais LMG, Reis JMSN, Pinelli LAP. Surface roughness and hardness of yttria stabilized zirconia (Y-TZP) after 10 years of simulated brushing. Rev Odontol UNESP 2014;43:379-83.

38. Papanagiotou HP, Morgano SM, Giordano RA, Pober R. In vitro evaluation of low- temperature aging effects and finishing procedures on the flexural strength and structural stability of Y-TZP dental ceramics. J Prosthet Dent 2006;96:154-64.

39. Rietveld HM. A method for including line profiles of neutron powder diffraction peaks in determination of crystal structures. Acta Crystallographica 1966;21:A228.
40. Rietveld HM. A profile refinement method for nuclear and magnetic structures. J Applied Crystallography 1969;2:65-71.

Corresponding author:

Dr Lígia Antunes Pereira Pinelli

Araraquara Dental School

Department of Dental Materials and Prosthesis

Rua Humaitá, 1680

Araraquara 14801 903, Sao Paulo

BRAZIL

Email: laizamgfais@foar.unesp.br

Copyright (C) 2016 by the Editorial Council for The Journal of Prosthetic Dentistry.

\title{
Noteworthy Abstracts of the Current Literature
}

\section{A systematic review of recall regimen and maintenance regimen of patients with dental restorations. Part 1: Tooth-borne restorations}

\author{
Bidra AS, Daubert DM, Garcia LT, Gauthier MF, Kosinski TF, Nenn CA, Olsen JA, Platt JA, \\ Wingrove SS, Chandler ND, Curtis DA \\ J Prosthodont Jan 2016. 25 Suppl 1:S2-15. http://dx.doi.org/10.1111/jopr.12417.
}

Purpose. To evaluate the current scientific evidence on patient recall and maintenance of dental restorations on natural teeth, standardize patient care regimens, and improve maintenance of oral health. An additional purpose was to examine areas of deficiency in the current scientific literature and provide recommendations for future studies.

Materials and methods. An electronic search for articles in the English language literature from the past 15 years was performed independently by multiple investigators using a systematic search process. After application of predetermined inclusion and exclusion criteria, the final list of articles was reviewed in depth to meet the objectives of this review.

Results. The initial electronic search resulted in 2161 titles. The systematic application of inclusion and exclusion criteria resulted in 12 articles that met the objectives of the study. An additional 4 articles were added through a supplemental search process for a total of 16 studies. Out of these, 9 were randomized controlled clinical trials and 7 were observational studies. The majority of the studies (14 out of 16) were conducted in the past 5 years, and most of the studies were conducted in Europe (10). Results from the qualitative data, on a combined 3569 patients, indicated that outcome improvements in recall and maintenance regimen were related to (1) patient/treatment characteristics (adherence to recall appointments, type of restoration and type of restorative material); (2) agent (chlorhexidine, fluoride, triclosan); and (3) professional interventions (repeated oral hygiene instruction, regular oral hygiene intervention).

Conclusion. There is minimal evidence related to recall regimens in patients with removable and fixed tooth-borne restorations; however, there is considerable evidence indicating that patients with tooth-borne removable and fixed restorations require lifelong dental professional maintenance to provide repeated oral hygiene instruction and regular oral hygiene intervention customized to each patient's treatment. Current evidence also indicates that use of specific oral topical agents like chlorhexidine, fluoride, and triclosan can aid in reducing risk for gingival inflammation, dental caries, and candidiasis. Therefore, these agents may aid in improvement of professional and at-home maintenance of various tooth-borne dental restorations. Furthermore, due to the heterogeneity of patient populations, restorations, and treatment needs, the evidence compels forethought of creating clinical practice guidelines for recall and maintenance of patients with tooth-borne dental restorations.

Reprinted with permission of the American College of Prosthodontists. 